\title{
A double-edged sword: the merits and the policy implications of Google Translate in higher education
}

\begin{abstract}
Machine translation, specifically Google Translate is freely available on a number of devices, and is improving in its ability to provide grammatically accurate translations. This development has the potential to provoke a major transformation in the internationalisation process at universities, since students may be, in the future, able to use technology to circumvent traditional language learning processes. While this is a potentially empowering move that may facilitate academic exchange and the diversification of the learner and researcher community at an international level, it is also a potentially problematic issue in two main respects. Firstly, the technology is at present unable to align to the socio-linguistic aspects of university level writing and may be misunderstood as a remedy to lack of writer language proficiency - a role it is not able to fulfil. Secondly, it introduces a new dimension to the production of academic work that may clash with Higher Education policy and, thus, requires legislation, in particular in light issues such as plagiarism and academic misconduct. This paper considers these issues against the background of English as a Global Lingua Franca, and argues two points. First of these is that HEIs need to develop an understanding and code of practice for the use of this technology. Secondly, three strands of potential future research will be presented.
\end{abstract}

Key words: academic writing, English for Academic Purposes, English as Lingua

Franca, Higher Education policy, academic misconduct

Klaus Mundt ${ }^{\mathrm{a}} \&$ Michael Groves ${ }^{\mathrm{b}}$

${ }^{a}$ Centre for English Language Education, University of Nottingham, UK

${ }^{b}$ Birmingham International Academy, University of Birmingham, UK, 


\section{Introduction}

The phrase "Educational Technology" is often a shorthand for digital technology in education, and a large amount of effort has been devoted to developing digital technologies to enhance the process of education. These developments are reflected in the field of English for Academic Purposes (EAP), which prepares students whose first language is not English for university study in an English language medium. Universities, as well as the private sector, are working hard to embed new technologies (Bousbahi and Chorfi 2015), such as Moodle (cf Caputi and Garrido 2015), into their educational programmes, into their educational programmes, in order to enhance and perhaps transform their educational provision.

However, the ease of access to digital technology has also had negative consequences, and among the foremost of these is the prevalence of plagiarism. In many ways, the ubiquity of the Internet on the university campus and beyond has enabled this, since the ease of "copy and paste" plagiarism has allowed students to lift passages of other writers' work quickly and easily (Flowerdew and Li 2007). It has, however, become clear to many scholars that plagiarism is not as simplistic as simple, deliberate and nefarious transgression. Instead, plagiarism has complex roots: some cultural, some ideological and some based in the notion of authorship and ownership (Pennycook 1996). In fact, certain behaviours, for example patchwriting, have come into focus. Patchwriting is using parts of sentences from sources and binding them together in a manner which is not yet a competent paraphrase, but goes beyond simply copying (Pecorari 2003; Ivanic 1998). This form of writing was once suspect, but is now seen by some as to be encouraged as part of the process of joining the academic discourse community (Ivanic 1998).

Another, relatively new, digital technology also has the potential to affect normal academic practice, especially for those who are not studying in a language of which they have full command. Machine Translation is now available for free, across a variety of platforms. It offers basic translation at an ever improving level, and is based on an increasingly thorough base of translated language. Services such as Google Translate are available for free on desktop and mobile devices. Just as free access to vast amounts of hypertext has transformed the process of higher education, it would not be unreasonable to expect that Google Translate (GT) and the like will affect normative educational practices for vast numbers of students who are not studying in their first language, or whose studies lead them to interact with users of other languages. 
Just as the opening of the web led to a reconceptualisation of plagiarism (Chandrasoma, Thompson, and Pennycook 2004 inter alia), and a redefinition of what is acceptable and what is not, this paper will make the case that similar debates need to take place about what roles Machine Translation, and more specifically GT. This is not to suggest that GT and web plagiarism are identical, or will develop in identical ways. However, we propose that there are certain parallels that can be drawn between them. We further argue here that it is imperative that this potential issue be recognised and addressed in a pro-active rather than a re-active manner. In addition, we problematize the notion that GT is an inherently innocuous technological development with a marginal role to play in the university of the future. Because of that, it requires attention at the level of policy. This paper will take a socio-pragmatic approach to the issue (Hoepfl 2006), and make the assumption that the technology will be used by student writers, either openly if sanctioned by institutional policies or clandestinely if not. Due to a lack of related empirical studies, this, at present, remains a hypothetical suggestion based on a common-sensical view of the growing ubiquity of the use of digital technology in general. The paper will then compare the use of GT to the developing understandings of plagiarism, and suggest that the use of GT in the teaching of English for Academic Purposes should be seen as an opportunity to develop best practices in teaching and learning. It will argue this in the context of English as a Lingua Franca. It will also argue that HEIs have the responsibility to address the issue of Machine Translation, and provide students and teaching staff with clear guidelines about what is and what is not acceptable use of this new technology. Finally, it will suggest three areas of potential research for the academic community to consider in relation to the use of Machine Translation.

\section{The (in)abilities of Google Translate}

The quality of the translations Google translate produces is far from ideal. It is generally accepted that the software is able to save time, but requires a good deal of postediting by a human expert (Austermühl 2011). van Rensburg, Snyman, and Lotz (2012) found that the quality of GT was far below the expected quality in a number of academic genres. The output of Google Translate has been investigated from the perspective of whether or not it is able to produce high quality texts (for example van Rensburg, Snyman, and Lotz 2012). However, this is to miss a key concept. 
A student studying in a language in which he has limited proficiency is not faced with the choice of producing polished language or using Google Translate. Rather, he is faced with the choice of using Google Translate or his own, far from polished, interlanguage. A recent study by Groves and Mundt (2015) has found that GT was able to translate Malay writing into English with around 64 errors per 1000 words of writing. Given that many grammatical errors consist of more than one word, this density of error is clearly noticeable. This is, however, to be compared with another study by Müller (2014) which shows that writing that has been awarded 6.5 IELTS has 92 errors per 1000 words. Thus, from a purely grammatical point of view, the output of GT approaches, if not actually exceeds, the minimum language requirement for a large number of English speaking universities.

Of course, grammatical accuracy is only a part, and many would argue, a small part of effective academic writing. Hyland, for example is a prominent voice who argues that academic writing is, at heart, a social activity, not one based purely at the level of grammatical competence (Hyland 2007, 2009). That is to say that writing is an activity that occurs within a community, and this community has a number of expectations and norms. There are a number of other features of effective writing that form part of effective EAP courses, from organising sentences into paragraphs, to reference and citation skills, to patterns of argument and adherence to other norms of the academic discourse community. In other words, academic writing clearly requires skills and abilities far beyond grammatical competence. It would seem that aspects of discourse competence and sociolinguistic competence are of greater importance to producing a successful academic text. GT not able to deal with these features - or at least it can only translate superficially from one language directly into another. It cannot take a paragraph that follows the norms of one form of culturally situated rhetoric and transpose it into another set of norms. Therefore, even if the writing meets all grammatical norms, it may still be misaligned with the target discourse community in many other ways.

An example of this can be seen through the lens of Metadiscourse. This is a set of features that allow the writer to interact with the text and the (imagined) reader. As described by Hyland and Tse (2004), it can be broken down into interactive and interactional elements, which show the organisation of the text and address the reader respectively. These are an important way for a writer to show the reader that they are adhering to the norms and expectations of their readership, and hence take part fully in the social activity of communication through writing. They also allow the writer to balance the epistemological 
conventions and requirements of their field. A key aspect of this is the deployment of hedging and boosting devices. These allow the reader to understand where the writer is withholding, and where she is emphasising the strength of the ideational content of the text. These devices include phrases such as "might be", "there seems to be", or "there is definitely". Web-based translation is unable to compensate for the difference in use of these features across different academic cultures (Mundt, Groves, and Csernus, 2015). For instance, if the source texts lacks hedging devices, GT will not add these to make the text more suitable for the target context. It will also not change convoluted sentences into more easily readable ones. That is to say, GT is unable to perform the switch of academic mindset a human writer can perform - it has no reader awareness.

Metadiscourse is one of a number of features that the system, as it presently stands, is unable to deal with. The system is unable to work with a complex web of issues such as textual symmetry (Clyne 1987) or any number of intercultural rhetoric-based issues (Connor 2011). For this reason, it is patently clear that, while it is improving its ability to create text that is coherent at the level of the sentence, there are significant issues that the translation software cannot overcome.

\section{The understanding and treatment of plagiarism}

According to Flowerdew and $\mathrm{Li}$ (2007), the nature of plagiarism is one that is very much rooted in Anglo culture and its specific notions of ownership of writing and knowledge. Moore Howard (2007) demonstrates how this concept of ownership developed through the 19th century and still informs thinking to this day, despite the protestations of Postmodernists and Poststructuralists who strive to distance the text from the author in order to focus on the meaning created in the reader. After all, in the assessment of university students, it is the achievement of their work, and, at least at doctoral level, it is their original contribution that decides over success or failure. Thus, in this context, it is unfeasible to view text as disengaged from its author.

In addition, the traditional norms of intertextuality are challenged by the technological developments of hypertext, which allows documents to be linked together, rather than simply referred to. This conception is culturally bound and therefore something that needs to be learnt by students who approach an Anglo academic culture from a different educational 
background in order to satisfy the expectation of a critical and analytical approach to synthesising and commenting on information and data.

Other strands in the academic literature on written plagiarism note that the issue is not simply a case of a violation or not. The understanding of the nature of patchwriting (Pecoari 2003) has developed well, and it is now well understood that poor paraphrasing is very often less an attempt to deceive, and more a symptom of poor ability to linguistically manipulate the ideas embedded in the writing. Ivanic (1998) makes the clear and cogent point that patchwriting is, in fact, a clear and welcome part of the learning process. For students to adopt the norms of a new discourse community, they need to experiment with them, and begin to take on some of the facets of that communication.

In terms of paraphrasing, then, the original notion of "plagiarism" has been replaced by the concepts of transgressive and non-transgressive intertextuality (Chandrasoma, Thompson, and Pennycook 2004). It is acceptable, or non-trangressive, for students to take phrases from expert writers in their field and appropriate them for use in their own work. There are even university-sponsored websites such as the Manchester Academic Phrasebank dedicated to assisting students to develop a range of set phrases for re-use. This is seen as good practice within the EAP community, and perfectly acceptable practice according to the academics interviewed by Davies and Morley (2015). This is on the assumption that the phrases adopted are not carrying the supposed opinion of the writer. The use of set phrases is now seen as part of the process of adapting one's use of language in order to become part of the academic discourse community.

Transgressive intertextuality is, on the other hand, unacceptable practice. Examples of this might include purchasing essays from other students or commercial providers. Interestingly, as a study in Malaysia by Ali, Ismail, and Cheat (2012) found, students were able to identify many examples of plagiarism, but did not regard buying essays or copying from a friend as plagiarism. However, it is unclear from the report whether students regarded these practises as acceptable, or unacceptable, but not defined as plagiarism. Motives for this form of plagiarism have been widely discussed, and include areas such as time constraints and lack of motivation. One of the more interesting ideas discussed by Pennycook (1996) is the idea that the students seem to think that paraphrasing is actually more nefarious - since the ideas that are being reported are not their own. By using the original source's own words, the writer may intend to be showing the informed reader that he or she has understood the original ideas in toto. 
What does become clear, then, is that plagiarism is not a simple issue, especially considering the distinction between nefarious and non-nefarious activity. One might argue that an attempt to deceive the reader into believing that a piece of text is the writer's own achievement when it actually is not, could be classified as plagiarism, while a poor paraphrase due to limited linguistic ability is not.

There is also a need to problematise the notion of plagiarism as a simple abuse of the technology. There are cultural, educational and social aspects at play, and student behaviour may present itself in a number of ways and for a number of reasons. This, then, has parallels with the use of Machine Translation, in particular from two perspectives; namely whether plagiarism can actually be detected and whether an English text that was machine translated from another source language can be said to be the student's own achievement. However, before considering these, we would like to examine the wider context of English in a globalised world, and then within an internationalised university. This debate will point to Google Translate as potential facilitator of communication, but it will also highlight a number of controversial points that will lead back to considerations of the use of this technology in the light of potential academic offense. It will further lead to considerations of notable drawbacks of using the technology, which, in turn, will allow for recommendations regarding the use of Google Translate in EAP and Higher Education.

\section{English, Englishes and Lingua Francas}

It has long been recognised that there are a number of varieties of English, and that these extend beyond the realms of the historical birthplace of the language. One of the most influential writers on this subject has been Kachru, who has described the use of English in the world as being in three concentric circles (Kachru and Nelson 2000). The inner circle is made up of the countries that were the earliest users of English, these being the UK, the USA, Ireland, Australia and New Zealand, where the English language has been canonised. The characteristic of these countries is the fact that, apart from a few exceptions such as Welsh, or Maori languages, the only working languages of the country is English. The outer circle is made up of countries that have had English imposed upon them though colonisation, including countries such as India, Malaysia and Nigeria. These countries use English as an official language for some purposes, and may have English deeply embedded in their education systems. Citizens of these countries are often bilingual (at the least). The final 
circle of Kachru's system is known as the "expanding circle". This involves countries that do not necessarily have a long relationship with the English language, but are learning it as it opens a number of opportunities in a globalised world. Here, the English language is a means of communication with other parts of the world and is not necessarily firmly canonised. It may thus diverge visibly from language norms in the inner circle. Kachru's ideas have been criticised for being slightly over-simplistic for example by McGee (2009), but it is a very effective conceptualisation of the roles that the language plays in various countries.

The unprecedented reach of English has led to a number of debates, within and outside the academic literature. One of the most important of these is over the much contested area of "ownership" of the language (Pennycook 1998; Crystal 2003). While some countries have a centralised authority to attempt to regulate the use of the language, such as the Academie Francaise, English has no such authority, with the possible exception of various prestigious dictionaries, who would only claim to describe, not prescribe usage (Oxford English Dictionary 2013). There is, however, a question of whether "native speaker" status can be assigned to users of the language from outer circle countries, especially if they use a highly localised form of English, such as Singlish in Singapore. Features of these forms of English have been well described. In the case of Singlish, for example, notable features include lack of auxiliary verbs, and also the additions of particles such as "lah" to add layers of meaning (Crystal 2003).

It has become clear that the form of English spoken in inner circle countries does not have an intrinsic value that makes it in any way superior to the many other Englishes spoken in other capital cities around the world. The general understanding is that use of language is judged on the appropriacy of the language for the situation (whether that be geographical, socio-economic or socio-cultural), not on its adherence to a set of grammatical or phonological norms (Sivasubramaniam 2011).

In addition to that, it has also become clear that the so called native speaker norms are in fact even less relevant, since so much of the communication in English in the world does not involve native speakers at all. As Kirkpatrick (2012) points out, English is the sole working language of ASEAN (The Association of Southeast Asian Nations), and yet for most of the countries in the association, there is little direct connection to English, in the manner of the inner or outer circle countries. This leads to a situation where both parties in a conversation are communicating in a language which is not their own. In other words, the situation within ASEAN is that of English as a Lingua Franca (ELF). 
Language, in this context, is a tool. Hence, ELF in itself is not a variety of English, although there are a number of features that are often shared (Seidlhofer 2004). Instead, it is language defined by context and purpose. As such, as Jenkins (2011) explains, there is a move away from traditional ideas underpinning conventional language learning, often known as English as a Foreign Language (EFL). ELF is global, not rooted in a certain geographical area. It is also based on the idea of difference, and not deficit - that speakers have to overcome a problem, not work toward a preconceived target. Also, it is based on ideas of contact and evolution, whereas the dominant metaphors in more traditional EFL are to do with fossilisation and interference. Whereas EFL will regard speakers of interlanguage as either aspiring or failed native speakers, ELF sees these speakers as successful and inclusive communicators.

Thus, the international use of the English Language is for people to communicate. English is not used because of some inherent superiority of its original users. It is the language that, for historical reasons, is most likely to be spoken by all of the interlocutors at the table. However, there is the potential to lead toward power inequalities in favour of a native speaker of the language.

The central tenets of adaptation and equality apply as much to the aspirations of ELF as they do to the lofty aspirations of Internationalised HEIs. There are, however, clear inconsistencies with this position, to which this paper will now turn.

\section{The place of English within the International University}

These discourses on the role and purpose of ELF reflect much of the writing on the subject of internationalisation that has taken place over the past few decades. For example, Knight $(2004,25)$ expresses the hope that "It may be optimistic, but it would be reassuring to think that social and cultural rationales for internationalization will be given equal importance as the economic and political one" - although she does later on in the same article question whether internationalisation will lead to cultural homogenization. In parallel to this, van der Wende (2010) cites intercultural understanding as a major driver of internationalisation. Universities also are keen to project an image of international partnership and not hegemony. This is evident, for instance, in the University of Bath's online international strategy, which states the aim to "support our intercultural awareness and our international community of staff and students on campus and overseas and develop and sustain world-class research by 
means of multilateral and bilateral partnerships in key strategic locations with pre-eminent universities in their respective regions" (University of Bath 2015). The discourse of community and partnership, avoiding national hegemonies, is surely to be applauded. Admirable though this may be, this approach is not without its complications.

Pincas discusses the changing role of English as universities internationalise and "virtualise" (2001, 40). She suggests that forms of standard English can be a manifestation of national prejudice, and that below the surface of other forms of English, there lie a number of prejudices related to "othering" in forms of English. There is a need, therefore, for students from other language backgrounds to either adopt the cultural norms of the host institution, or remain somewhat marginalised, at least on an unspoken level.

As Jenkins (2011) points out very clearly, there is a fundamental contradiction at the heart of Internationalisation - the role of English and the acceptable dialects of English. At present, universities demand English language tests in the languages of the inner circle countries, despite the test writers' efforts at diversity. This means that students' language is judged as flawed, or deficit, if they are speaking the languages of outer circles countries. She (Jenkins 2011, 934) makes the clear point that, "It is a contradiction for any university anywhere that considers itself international to insist on national English language norms". In practice, this means that a native speaker of, for instance, Nigerian or Malaysian English may be told that their English is insufficient for study at an English-speaking university, despite that fact that it may be their first language or one of their first languages. That this is problematic, there can be no doubt. It also seems to presume that the native speaker of the 'right' variety of English is a more apt academic writer a priori, which seems questionable, seeing as language proficiency is only part of academic literacies. It seems as if this has already been recognised in the USA, where many College Writing 101 courses are compulsory for undergraduate students regardless of their origin.

Given that universities seems to aspire to a multi-focussed internationalism, where the opportunities are equal for all-comers, regardless of nationality, it would seem axiomatic to adopt a culture of English as Lingua Franca within the cultures of HE. However, this does not remove the need for mother-tongue users of languages other than English to be educated to a level of English that allows them sufficient competence to become part of the academic discourse community. The CEFR would place this at communicative competence level C1 or C2 - the result of 1000s of hours of study. This is a major commitment, and one which takes an enormous amount of time and effort, whether it be part of the school curriculum in a 
student's home country or not. This is necessary, at the moment, for any student aspiring to study in an English Language Medium University if they are raised without English as a first language. It must also be borne in mind that this is to reach the minimum level for study, in many cases, with all the attendant power-differences discussed above.

\section{Google Translate as a partial solution to these issues}

Therefore, if the purpose of English is as a genuine lingua franca, and it is meant to enable communication between language users from different backgrounds, and not to enable or empower users from a particular background, it would seem an obvious move to allow it to some extent within the academy. It has there the potential to contribute to a reduction of the gaps caused by language inequality in the academy and allow students from different language backgrounds the opportunity to participate on a more level footing. Of course, this would mean that the Anglophone academic 'host' culture needs to recognise ELF as a valid way of appropriate communication and let go off a number of expectations in terms of 'traditional' language norms.

There is also a technological aspect to this. The use of GT has the potential to allow users of English as an Additional Language to circumvent some of the differences in the language and work on the same linguistic level as their peers. Further, GT has the potential to remove the inherent power differentials as discussed by van Parijs (2007) bringing greater equality to all users of English. It could remove the "native speaker" as the point. of reference. (Philippson 1992; Kachru 2009; Halliday 2009). Thus, computer translated English could be seen as a culturally neutral dialect, belonging to everybody and nobody - a linguistic third space.

Further, the new technology has the potential to allow a greater change to happen. Given that the technology is constantly developing and improving, potential students who are not born into the dominant language group are perhaps able to bypass the need to learn languages. Therefore the academic community needs to question the reason for having enforced language requirements. Is the use of formal English to be a shibboleth - the users having to prove linguistic competence before they are able to enter into the community - or, is language competence seen more as an enabler? The former seems unjust, as it appears to pre-suppose that important ideas and valid research and academic merit are linked to the ability of speaking English. The former takes a more humanistic turn, as it seems to 
emphasise the actual ability to communicate in an English-speaking social environment. Yet, if efforts at 'internationalisation' are to be taken seriously, the question may well be posed whether internationalisation means that everyone has to speak English. The fact is that it currently does, and in this case the shared language is seen as a way to communicate and nothing more. The vast literature on the conceptualisations of English as a Lingua Franca show that this is the primary goal of many users of English in a globalised world. Therefore, the need to communicate overcomes the need to conform to a certain number of, perhaps mythical, linguistic norms.

Certainly, there is no easy way to learn a language such as English without a great deal of effort and expense, either on the part of the institution, or the individual. Users must spend a number of weeks or months in exclusive study of the language before they enter the university. If a freely available and effective technology is able to allow the students to bypass this very difficult and time-consuming process, then it would be difficult to make the case that the students should ignore the technology and return to the classroom for their slow and strenuous study - if communication is the only goal of their being at the university; in which case GT and similar technologies are clearly an enabling factor.

\section{Use of translation software as an academic offense?}

One question that arises in this context is whether the use of Google Translate should be seen as an academic offense. Certainly, there is a need for HEIs to legislate about the use of the system in some cases. For example, a student may feel tempted to use a source verbatim in their original language and use the translation software in order to disguise the plagiarism. They might even take an English source and use the software twice, once to translate the text out of English, and once to translate the output back into English, thus avoiding detection by software packages. This is clearly plagiarism with an intent to deceive, and therefore would need some form of official institutional censure.

However, a student who writes their own text partly or wholly in their first language, and then uses the translation software to translate the more difficult passages into English is committing an offense in the sense that the work they is submitting is theirs, but could not be truly said to be theirs in totality. The expression of the concepts and notions, a key part of the membership of an academic community, would not be the work of the student. However, this is open to question as to whether what the student was doing was any more or less serious 
than asking a friend (or paying a stranger) to proof read work before submission. After all, if what is important in the academic community is critical merit, originality of ideas and a contribution to knowledge, then writing in one's own language and translating the text by means of technology should be acceptable, given that the content does not suffer significantly in the translation process. The intellectual merit, then, would still be the student's. While there may be valid reasons for opposing the propagation of translation as coping strategy for student writers, it is important to remember that the academic community seems all too happy to read translations of accomplished writers and philosophical classics from Plato, to Kant, to Foucault - translations without which Anglophone academia would be rather self-contained.

It has already become clear that the epistemological balance of different types of academic writing cannot be transferred between languages using translation software. This is also true of features of academic writing from building paragraphs to the expression of complex argument. Therefore, if a student is to use translation software in order to create a polished piece of work, they will need to ensure that a number of norms and expectations need to be addressed before or after the translation happens. In other words, they will have to ensure that issues such as the expression of certainty is within the norms of the target discourse before the translation or added later through post-translation editing. Therefore, it would not be unreasonable to argue that they have engaged with the deeper academic literacies, and the relatively superficial barrier of first language should not play a greater role than absolutely necessary in the student's learning, and expression of such. After all, students have signed up to excel in and contribute to their academic disciplines - not to excel at the use of English.

In addition, the use of technology to support native speakers in their writing is already embedded in the academic process, and remains uncontroversial. Whether the writer is using Microsoft Word or Google Documents, the word processor that she uses is already working to highlight orthographical transgression, and suggest improvements. In many programmes, "auto-correct" features will detect and correct spelling errors before they are even noticed by the writer.

Users who study in an additional language also have a number of other technological aids to help their language development. The EAP community has long championed effective and informed use of dictionaries in order to enhance the development of language proficiency and versatility. There is an industry involved with the writing of software to aid students' acquisition and retention of English to assist their transition from L2 academic neophytes to 
competent users of the language and hence become effective members of the academic community. Technological assistance in education has become the norm. Therefore, judicious use of the technology would seem to fit in well with a long tradition of technology acting as an aid to scholarship. This means that Machine Translation is not set to replace language acquisition. It can be usefully utilised to facilitate the communication of valuable ideas and knowledge.

\section{The drawbacks of this approach}

This is not, of course, to espouse some form of techno-utopianism, or even technodeterminism, and suggest that online translation software will bring an end to the linguistic issues faced in an international scholarly community. There are a number of things that the translation software is unable to do, and it will take a number of large leaps forward in artificial intelligence before this can happen.

First among these is the issue of epistemological balance and intercultural rhetoric. For many years the English language teaching community has recognised that effective language use is not about the use of grammar alone. Instead, since the purpose of language is communication, language education needs to operate at a number of levels, from the sentence level to the level of discourse and sociolinguistic appropriacy. This is also true of university level writing - writers need to apply the norms and conventions of the academy, in order to be part of the social process of writing (Hyland 2009). Going back to Kaplan's (1966) (probably flawed) original study, there are differences in the way that arguments are expressed across cultures. These norms include patterns of organization, as, for example, identified by Swales (1990). Even at the level of grammatical accuracy, there are certain tendencies that academic writers tend to follow, for example the practice of creating complex and semantically dense noun phrases (Biber 2006). Translation software has no ability at present to adapt to these differing norms of sociolinguistic practices.

In addition to this there are a number of generic differences academic writers need to deal with. These may be task-specific, for example the nature, structure and purpose of an essay as compared to a report. In addition there are discipline specific issues. These include issues of levels of intertextuality, metadiscourse and systems of discourse moves (Connor 2011). 
A second issue to be dealt with is the different types of communication necessary at university. It is clear that formal lecture-based learning and written assessment is only part of the process of studying at a university. The opportunities for social interaction and personal enrichment, aside, the opportunity for what Marsick and Watkins (2001) term "Informal and Incidental learning" is crucial for students. They describe this learning as unplanned and haphazard, but it is clearly an important part of the student experience. Online Machine Translation is, as yet, unable to work at the speed needed to take part in the discussions and conversation in which informal and incidental learning happens.

Even if students are able to record and translate lectures, and write assessments using online translation, then this still leaves them lacking in their ability to communicate clearly and effectively in face to face situations. They would be unable to make significant contributions to discussions and seminars, individual conversations with their supervisors, tutors and peers, and the like.

In addition to this, it seems clear that flipping classrooms is going to become an established feature of university teaching (Alvarez 2011). This approach takes the transmissive aspect of education and places this online, replacing large lecture theatres with online lectures and using face to face time for cooperative problem solving. This approach relies on spontaneity of communication and cooperative abilities of students. The current state of the art of machine translation claims to be able to translate voice communication, but this is slow and inaccurate. It is also based on written, not spoken corpora, which have very different rules and conventions (Adolphs and Carter 2013). Therefore students who rely on the use of translation software instead of developing their own language skills would be unable to contribute to collaborative and meaningful communication.

\section{Recommendations}

Firstly, the use of Google Translate is an area where a great deal of research is needed and it is suggested that this could happen in three directions. Firstly, the capabilities of the software need to be understood, and this needs to be done on a variety of levels, but with the general aim of understanding what the software is and is not able to produce in terms of aligning itself to academic norms. An understanding is needed of how far the system is adept to the generic conventions of academic writing in the various disciplines, as it continues to be developed by its provider. In addition, an understanding is needed of how far the 
sociolinguistic norms and expressions of academia are met in the translation given different qualities of the original text. In other words, what conditions have to be met in the students' writing in L1 in order for the translated text to be effective as a piece of academic writing. There are variety of research approaches that could be adopted, from corpus analysis to critical discourse analysis in terms of whether or how far sociolinguistic features are transferred from one language into another through GT.

The second area of potential research involves stakeholders' attitude towards the use of the technology. Stakeholders include academic staff, students of all nationalities, and university administrators, as well as possibly employers. Before a consensus on the use of the technology can be arrived at, an understanding needs to be gained of the dominant beliefs and attitudes towards the technology from all relevant viewpoints.

The third area of potential research is aimed at an understanding of how the technology can be incorporated into the learning process, both at Pre-sessional stages and Insessional. The EAP community can take this technology, and develop a set of classroom techniques that allows the software help students facilitate and accelerate the initial, labour intensive period of language learning and acquisition, and quickly move on to addressing deeper academic literacies and intercultural questions. It is hoped that this would allow learners to be able to better adapt to the environment in which they are studying. This is not to suggest that the EAP community should abandon itself to machine translation. As discussed above, there is little likelihood that the software can replace development of competence is English, at least in an effective student's work. However, it is likely that, used carefully, and with imagination, the software can be used to aid the language learning process, not replace it.

Beyond a research agenda, HEIs should be prepared to legislate on the use of GT and its counterparts from other producers in order to prevent potential policy shortfalls that might leave a number of grey areas in their quality assurance frameworks. One possible approach is to suggest a libertarian approach to the use of translation software. This approach would allow the use of the software in any way, and as long as the final product met certain standards, the work would be accepted. Alternatively, a more holistic approach to student development could be adopted. This would suggest that effective cross-lingual and crosscultural communication skills are essential for a graduate of any university, and for this reason students have the responsibility to develop these skills and therefore will not be permitted to support their communication with GT. 


\section{Conclusion}

It is the hope of the authors that HEIs will adopt a position somewhere between these two positions. Google Translate clearly has an effective part to play in the future of transnational education, and can help students and staff cross linguistic boundaries more easily and faster. However, it cannot replace the need for students to learn effective and high level communication to be able to play a full role in the academic community. It is just as important to understand the limitations as well as the abilities of any technology, and not use it uncritically. A parallel can be drawn with the emergence of Web-based plagiarism. The understanding of plagiarism shifted to take into account that not all intertextuality was transgressive, and non-transgressive intertextuality could and should play a part in the development of the student's skills.

\section{Notes on Contributors}

Klaus Mundt holds an MA in Southeast Asian Studies and in Applied Linguistics \& ELT and develops and teaches insessional EAP programmes as well as convening and teaching modules for the MA CETI/MA Translation Studies at the University of Nottingham. His main research interests lie in cultural translation, intercultural communication and genre and register analysis.

Mike Groves has been involved in the teaching of English language for over 20 years, and the teaching of University English for approaching 10 of those. He is currently responsible for the EAP components of the University Pathway programmes at the University of Birmingham. He is interested in how technology works for and against the interests of students, instructors and institutions.

\section{References}

Adolphs, S., and R. Carter. 2013. Spoken corpus linguistics: from monomodal to multimodal. Abingdon: Routledge.

Ali, W.Z.W, H. Ismail, and T.T. Cheat. 2012. "Plagiarism: To What Extent it is Understood?" Procedia - Social and Behavioral Sciences 59: 604-611. doi:10.1016/j.sbspro.2012.09.320. 
Alvarez, B. 2011. "Flipping the classroom: Homework in class, lessons at home." Education Digest: Essential Readings Condensed For Quick Review 77 (8): 18-21. Austermühl, F. 2011. "Of clouds and crowds: Current developments in translation technology." Translation in Transition. Accessed April 302014.

\section{http://www.t21n.com/homepage/articles/T21N-2011-09-Austermuehl.pdf}

Biber, D. 2006. University language: A corpus-based study of spoken and written registers. Amsterdam: John Benjamins.

Bousbahi. F, and H Chorfi. 2015, "MOOC-Rec: A Case Based Recommender System for MOOCs", Procedia - Social and Behavioral Sciences 193 (3): 1813-

1822. doi:10.1016/j.sbspro.2015.06.395.

Chandrasoma, R., C. Thompson, and A. Pennycook. 2004 "Beyond Plagiarism:

Transgressive and Nontransgressive Intertextuality." Journal of Language, Identity \& Education 3 (3): 171-193. doi:10.1207/s15327701jlie0303_1.

Caputi, V., and A. Garrido. 2015. "Student-oriented planning of e-learning contents for Moodle.” Journal of Network and Computer Applications 53: 115-127. doi:10.1016/j.jnca.2015.04.001.

Clyne, M. 1987. "Cultural differences in the organization of academic texts.” Journal of Pragmatics 11 (2): 211-241. doi:10.1016/0378-2166(87)90196-2.

Connor, U. 2011. Intercultural Rhetoric in the Writing Classroom. Ann Arbor: The University of Michigan Press.

Crystal, D. 2003. English as a Global Language. 2nd ed. Cambridge: Cambridge University Press.

Davis, M., and J. Morley. 2015. "Phrasal intertextuality: The responses of academics from different disciplines to students' re-use of phrases." Journal of Second Language Writing, 28: 20-35. doi:10.1016/j.jslw.2015.02.004.

Flowerdew, J., and Y. Li. 2007. "Language Re-use among Chinese Apprentice Scientists Writing for Publication.” Applied Linguistics 28 (3): 440-465. doi:10.1093/applin/amm031.

Google (2012) “Breaking down language barriers.” Accessed February 22013. http://googletranslate.blogspot.co.uk/2012/04/breaking-down-language-barriersixyears.html 
Groves, M., and K. Mundt. 2015. "Friend or foe? Google Translate in language for academic purposes.” English for Specific Purposes 37: 112-121.

doi:10.1016/j.esp.2014.09.001.

Halliday, M.A.K. 2009. "Written Language, Standard Language, Global Language.”

In The Handbook of World Englishes, edited by Braj Kachru, Yamuna Kachru, and Cecil Nelson, 349-365. Oxford: Wiley-Blackwell.

Hoepfl, M. 2006. "The Evolution of Technology Education in the United States: The Case of North Carolina." In International Handbook of Technology Education: The State of the Art, edited by Marc deVries, and Ilja Mottier, 95-112. Rotterdam: Sense Publishers.

Hyland K., and P. Tse. 2004 "Metadiscourse in academic wiring: a reappraisal." Applied Linguistics 25 (2): 156-177. doi:10.1093/applin/25.2.156.

Hyland, K. 2007. Writing in the Academy: Reputation, Education and Knowledge.

London: Institute of Education.

Hyland, K. 2009. Academic Discourse: English In A Global Context. London:

Bloomsbury Academic.

Ivanic, R. 1998. Writing and Identity: The discoursal construction of identity in academic writing. Amsterdam: John Benjamins.

Jenkins, J. 2011 "Accommodating (to) ELF in the international university." Journal of Pragmatics 43 (4): 926-936. doi:10.1016/j.pragma.2010.05.011.

Kaplan, B. (1966) Cultural Thought Patterns in Intercultural Education. Language Learning 16 (1): 1-20. doi:10.1111/j.1467-1770.1966.tb00804.x.

Kachru, B. (2009) 'World Englishes and Culture Wars'. In The Handbook of World Englishes, edited by Braj Kachru, Yamuna Kachru, and Cecil Nelson, 446-471. Oxford: Wiley-Blackwell.

Kachru, B., \& Nelson C. (2000) "World Englishes." In Analysing English in a Global Context: A Reader, edited by Anne Burns, and Caroline Coffin, 9-26. Florence, KY, USA: Routledge.

Kirkpatrick, A. 2012. "English as an Asian lingua franca: the lingua franca approach and implications for language education policy." Journal of English as a Lingua Franca 1 (1): 121-140. doi: 10.1515/jelf-2012-0006. 
Knight, J. 2004. "Internationalization Remodeled: Definition, Approaches, and Rationales." Journal of Studies in International Education 8 (1): 5-31. doi:10.1177/1028315303260832.

Marsick, V., and K. Watkins. 2001. "Informal and incidental learning." In The New Update on adult learning: New directions in adult and continuing education, edited by Sharan Merriam, 25-34. San Francisco: Jossey-Bass.

McGee, K. 2009. "Attitudes towards accents of English at the British Council, Penang: What do students want?" Malaysian Journal of ELT Research 5: 162-205. Accessed October 252010.

http://www.melta.org.my/modules/tinycontent/Dos/20091103$\underline{1336 \_99224 \_K y l e \% 20 M c G e e \_2009 . p d f}$

Moore Howard, R. 2007. "Understanding "Internet plagiarism"." Computers and Composition 24 (1): 3-15. doi:10.1016/j.compcom.2006.12.005.

Müller, A. 2015. "The differences in error rate and type between IELTS writing bands and their impact on academic workload." Higher Education Research \& Development 34 (6): 1207-1219. doi: 10.1080/07294360.2015.1024627.

Mundt, K., M. Groves, and A. Csernus. 2015. "Exploring Opportunities: The Impact of Google Translate on EAP Teaching." Manuscript submitted for publication. Oxford English Dictionary. 2013. "Guide to the Third Edition of the OED." Accessed August 6 2015. http://public.oed.com/the-oed-today/guide-to-the-third-edition-of-theoed/

Pecorari, D. 2003. "Good and original: Plagiarism and patchwriting in academic second-language writing." Journal of Second Language Writing 12 (4): 317-345. doi:10.1016/j.jslw.2003.08.004.

Pennycook, A. 1996. “Borrowing Others' Words: Text, Ownership, Memory, and Plagiarism.” TESOL Quarterly 30 (2): 201-230. doi:10.2307/3588141.

Pennycook, A. 1998. English and the Discourses of Colonialism. Abingdon: Routledge.

Phillipson, R. 1992. Linguistic Imperialism. Oxford: Oxford University Press Pincas, A. 2001. "Culture, cognition and communication in global education." Distance Education 22 (1): 30-51. doi:10.1080/0158791010220103. 
Seidlhofer, B. 2004. "Research Perspectives on Teaching English as a Lingua Franca." Annual Review of Applied Linguistics 24: 209-239.

doi:10.1017/S0267190504000145.

Sivasubramaniam, S. 2011. "Constructivism in EIL: Issues and Insights for Teaching and Research." Journal of English as an International Language 1: 1-21. Accessed August 182012.

http://www.eilj.com/images/pdf/eil\%20may\%202011\%20issue\%201.pdf

Swales, J. 1990. Genre Analysis: English in academic and research settings.

Cambridge: Cambridge University Press.

University of Bath. 2015. “International Strategy.” Accessed July 152015.

http://www.bath.ac.uk/about/organisation/strategy/international

van der Wende, M. 2010. "Internationalization of Higher Education.” In International Encyclopedia of Education. 3rd ed, edited by Penelope Peterson, Eva Baker, and Barry McGaw, 540-545. Oxford: Elsevier. doi:10.1016/B978-0-08-044894-7.008368. van Parijs, P. 2007. “Tackling the Anglophones' free ride: fair linguistic cooperation with a global lingua franca." In Linguistic Inequality in Scientific Communication Today, edited by Augusto Carli, and Ulrich Ammon, 72-86. AILA Review 20, Amsterdam: John Benjamins.

van Rensburg, A., C. Snyman, and S Lotz. 2012. “Applying Google Translate in a higher education environment: Translation products assessed." Southern African Linguistics and Applied Language Studies 30 (4): 511-524.

doi:10.2989/16073614.2012.750824. 